\title{
Understanding the challenges of e-learning during the global pandemic emergency: the students' perspective
}

\begin{abstract}
Purpose - The current study debates and highlights the challenges faced by university students regarding e-learning during the global pandemic emergency. Furthermore, it sketches the solutions of e-learning using a theoretical lens of Emergency Management Theory (EMT). Finally, the study argues a case for improvement in existing e-learning systems to enable higher education systems, particularly in a developing country, to recover the losses and increase education quality.
\end{abstract}

Methodology - A qualitative research design and phenomenology research approach were applied to conduct the current study. A total of 10 in-depth online interviews were recorded from students studying in Pakistan and the United Kingdom. Verbatim transcriptions were analysed using the reflexive thematic analysis approach.

Findings - The current study results explained in detail the numerous challenges, including lack of preparedness (students and institutions), low quality of interaction, lack of motivation, lack of class activities, and forceful adoption of e-learning. Alternatively, few opportunities also emerged through a set of suggestions such as a comprehensive emergency management plan, introduction of strong student counselling programs, and a strategic plan for quality of online learning content.

Originality - This study's contribution stands out in crucial times global pandemic. Emergency management theory is applied to understand the different dimensions of preparedness, response, mitigation, and recovery from a students' perspectives. Furthermore, considering students as important members of higher education institutions and understanding students' opinions regarding quality assurance during the global pandemic was imperative.

Keywords Challenges; e-learning; students; the global pandemic emergency; Pakistan; United Kingdom 


\section{Introduction}

Social interaction and well-being have been heavily impacted due to the rapid spread of the novel coronavirus global pandemic. Declaration of the global pandemic as a global emergency (Sohrabi et al., 2020), mainly social distancing, became a new normal (Weeden and Cornwell, 2020). Due to this global emergency, higher education institutions face hurdles to support students and teachers in learning (Rieley, 2020). As a result, profound changes are incorporated into the education delivery processes (Murphy, 2020). Since, social and physical distancing is imperative; therefore, higher education institutions have been closing and moving towards virtual systems to support global safety initiatives. This situation brings e-learning an alternative to a physical class environment (Liguori and Winkler, 2020). However, this transformation came with implementation and management hurdles. As for some universities, this was more difficult than others. Similarly, it is more difficult for some students to adapt to the new normal for some students.

Although digital technologies have become a new mode of studying around the globe (Singh and Thurman, 2019), even before the global pandemic emergency, and the delivery to the masses is becoming possible through digital technologies (Henderson et al., 2017). However, higher education is still considerably disintegrated by the experience of the students. According to Wright et al. (2014), students get empowered through these digital technologies with the fundamental interaction challenges. More importantly, face-to-face and digital contexts got different perceptions from teachers' perspectives, too (Jensen, Price and Roxå, 2019). It has been challenging to move into online education for regular face-to-face classes (Murphy, 2020; Bacow, 2020). This challenge becomes more critical for developing countries, as comparatively, these countries face more challenges regarding infrastructure, affordability, and readiness. Risk reduction involves relatively less focus in developing countries (Kreft et al., 2013). However, there is a limited body of knowledge exploring hurdles faced by the educational institutions in the developing nations regarding e-learning (Ramaiah, 2014).

During global health crises, virtual learning is the only option to continue education with fewer consequences. Therefore, regardless of different types of hurdles, virtual education is implemented around the globe. On one side, educational institutions are trying to minimize the potential damages through virtual learning, but on the other side, academics, particularly, are facing serious 
challenges. Thus, there is a dire need to study the problems and challenges they face to reach out for some workable suggestions for improvement.

In this regard, contextual differences are there; every country responded to this emergency according to their preparedness. Therefore, a study is considered important to dig out the students' experiences during the global pandemic emergency regarding e-learning. Furthermore, a comparison of developed and developing countries could be helpful to understand the phenomena better. For this reason, the current study is designed to explore higher education challenges and prospects through the student lens and translated it into the following research questions:

RQ1: What type of challenges did the students from a developing country face during the current emergency (global pandemic)?

RQ2: What type of challenges did the students from a developed country face during the current emergency (global pandemic)?

RQ3: What could be the possible contextual solutions for higher education institutions?

To answer the questions mentioned above, emergency management theory provided a theoretical basis to conduct the study. Emergency management can be viewed as the area and profession that involves the application of the concepts of planning, management, science and technology to counter the effects of extreme circumstances that have the potential to incur extensive harm, injury, and damage to the lives and property of a large number of people and which may result in the disruption of everyday community life (Soroya et al., 2020).

\section{Underpinning emergency management theory (EMT)}

According to EMT, timely implementation of emergency management can effectively handle the situation (Knox and Haupt 2015). The predicted and unpredicted emergency events need to be addressed by efficient strategies, policies, technology, and people through emergency management (Prasolova et al., 2017). The global pandemic is an alarming situation for every walk of life, especially the education sector. The profession and field of emergency management have progressed into more collaborative activity since the 1940s and 1950s. Figure 1 displays four stages of emergency management theory, preparedness, response, mitigation, and recovery.

Preparedness develops operational capacities through activities, i.e., exercises and training, resource management plans, public information in an emergency, mutual aid agreements, and 
communications. In a crisis, the response is an appropriate set of actions to save people and avoid property damage and casualties (Wang, Pan and Guang-wang, 2005). At the same time, the level of the continuing threat to human life and property from human-made and natural vulnerability can be minimized by adopting mitigation activities. E.g. safety codes, risk mapping, insurance of disaster, building codes, land-use management, disincentives, and tax incentives. Recovery is quickly taking activities of response before, during, or directly after the emergency. It helps save lives and curtail property damage and recovery by, e.g., shelter evacuation, emergency medical support, reception, and care, manning emergency operations centres and rescue. Recovery consists of short-term activities, including minimum operating standards and long-term activities, bringing life to be normal and restore vital life-support systems.

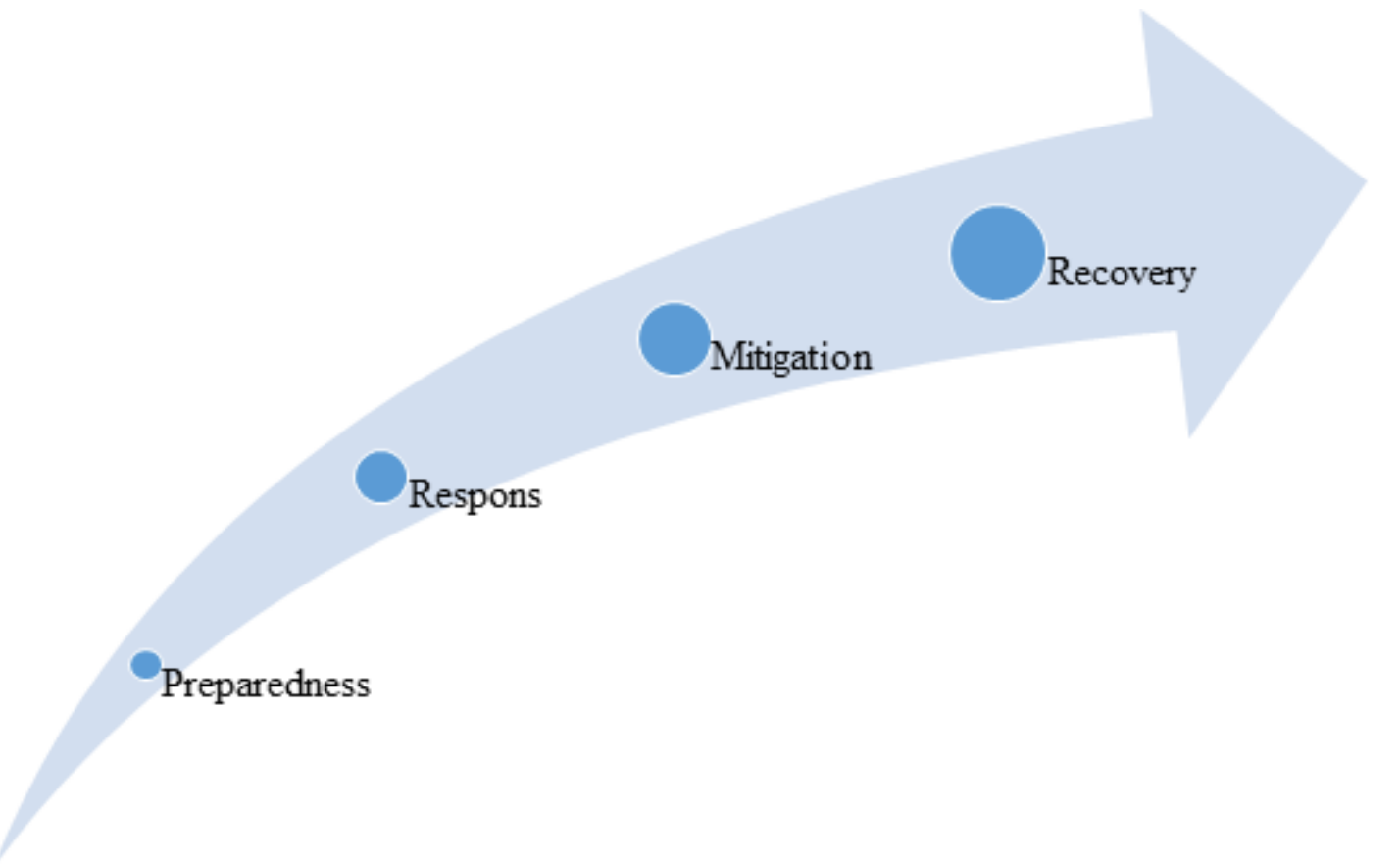

Figure 1. Stages of Emergency management theory (adapted from Wang et al., 2005)

\section{Literature review}

\section{E-learning - comparison of developing and developed country context}

Allama Iqbal Open University introduced the trends of e-learning in Pakistan in 1974. The Higher Education Commission (HEC) of Pakistan has encouraged higher education institutions to incorporate e-learning platforms. Along with AIOU, the Virtual University of Pakistan was established in 2002 to initiate distance learning. Out of 225 HEC, Pakistan recognized universities, 
only $2(0.88 \%)$ universities offer e-learning (HEC, 2021). However, the global pandemic has changed the scenario, and all universities in Pakistan started to build e-learning platforms to practice safety measures for all stakeholders in the educational environment. Recent studies focused on advanced educational technologies such as augmented reality in the adoption intentions of e-learning (Saleem et al., 2021) and mobile learning technologies (Asghar et al., 2021) in Pakistan during the global pandemic.

Contrary to Pakistan, concerning increased digital technology usage, digital technology, including personal digital devices and ICT, has helped transform UK higher education (Pimmer, 2016). While the global pandemic has accelerated the switch to digital technology, it is important not to see this as the only driver in the movement to new forms of education because this shift has taken time in the UK (Zhou and Milecka-Forrest, 2021). According to STATISTA (2020), students with age 16 to 34 are accessing online courses (37\%) and e-learning materials (70\%) in the UK. It seems the e-learning adaptability trends are quite high compared with Pakistan (emerging educational technology context), where Pakistan is facing numerous challenges in adopting e-learning education (Saleem et al., 2021).

Recent renewed interest in online and distance learning in developing and developed countries has become a new paradigm shift (Simpson, 2018). More importantly, the mechanism of distance education among the developing and developed countries (Saavedra, 2020) speculates on the technological divide, and students from different countries face various yet severe challenges. At the same time, in developing countries, e-learning systems transform moderately in the current global pandemic crisis via the emerging native technologies sectors (Affouneh et al., 2020). Muries and Masele (2017) suggested a need to explore the factors of embracing e-learning in developing countries, especially in higher education institutions.

The students at large were not prepared in the developing countries to adopt the changes in the upcoming educational reforms in the form of computer technology (Shehzadi et al., 2020). Apart from the technology accessibility, there is still a need for a stable electricity connection, reliable access to the internet, and appropriate infrastructure to adopt e-learning (Adnan and Anwar 2020). Besides, there is a gap in digital knowledge among developed and developing countries based on different adaptability levels among students and teachers (Eltahir, 2019; Affouneh et al., 2020). Hence, it would be greatly attractive to understand different mechanisms of rapid e-learning adoption in developing and developed countries. 


\section{E-learning and student adoption perception}

Education technology is becoming increasingly central, but the demand for e-learning is highly relevant to simulated learning experiences and authentic learning opportunities (Eltahir 2019). At the beginning of e-learning implementation, teachers have focused on sustaining classical learning (Basilaia, 2020). Since e-learning has proven to be an ideal response to the global pandemic (Siron et al., 2020). E-learning has been demonstrated by the technologies' features such as 'perceived utility' and 'friendly use' (Renda dos Santos and Okazaki, 2016; Al-Samarraie et al., 2018). Transforming higher education through online education enables students to share a sense of responsibility and responsibility (Bond et al., 2018). So, it will be plausible to explore key challenges faced by students during the online learning environment and its adaptability.

Moreover, COVID-19 and online teaching in higher education have a tremendous change in the adoption given numerous challenges, online learning experience, online learning technological support, and contextual understanding for higher education to sustain social distancing (Bao, 2020). Considering the growing importance of e-learning due to pandemics worldwide, the

prevailing feature of virtual education is more interactive; however, online learning could move towards self-paced programs for students (Fisher and Coleman, 2001). The current study explores students' life experiences in a global pandemic context regardless of the essence of theoretical differences between virtual and online educational platforms. These experiences influence student satisfaction, loyalty, word-of-mouth communication and re-enrollment intentions (Rehman et al., 2020). The outcome of the present study revolves around identifying diverse challenges such as lack of Information Communication Technology (ICT) infrastructure, technical skills gap, and financial hurdles in the adoption of e-learning platforms. In this vein, students lacked accessibility to attend their online classes during a pandemic emergency in Pakistan. There are several barriers, such as the non-availability of e-learning systems, lack of technical support, poor quality of security and privacy, the low-quality curriculum in the adoption of e-learning in Pakistan (Shehzadi et al., 2020). In contrast, the e-learning system is well established in developed countries (Sharpe and Benfield, 2005). Given the adequate technology infrastructure and high adaptability, UK students might have adopted fewer consequences to the emergency learning strategies implemented at their university (Zhou and Milecka-Forrest, 2021). 


\section{Methodology}

\section{Study setting}

In the global pandemic, the importance of e-learning has increased for universities and university students. The current study looks at higher education school students' challenges and prospects in the UK and Pakistan. In the global pandemic, contextual understanding of student experiences in terms of online learning is crucial. In the study in hand, a description of the experiences of elearning during this global pandemic has been given to the students. As a developing country, Pakistan has a different response to this emergency than the United Kingdom for e-learning. To date, Pakistan has only two universities that offer e-learning. However, in the United Kingdom, all higher education institutions established the e-learning model for higher education. Phenomenology, as a research approach, was employed for this study (Mayhew, 2004).

Moreover, the current study explores the various dimensions of a lived experience about a phenomenon through the application of phenomenology (Cresswell and Poth, 2007) that enabled researchers to comprehend the challenges and prospects of e-learning. According to Fuster Guillen (2019), phenomenology as a research method helps explore life through experiences and improves contextual understanding. Based on the research objectives, participants were expected to share their real-life experience about e-learning experience and contextual understanding, given the UK (technologically advanced) and Pakistan (technologically emerging) contexts. Following the core of students' e-learning experiences, exploring the conscious connectivity with the global pandemic, comparison in the thought processes of before and during the global pandemic as stages of emergency experiences, how higher education institutions in the UK and Pakistan have been approached and addressed. The contexts of developed and developing countries were chosen to understand similarities and differences for higher education institutions' policymakers, as comparative studies give more cross-cultural comparisons and adaptation of best practices (Saeed, 2007). Cross-cultural represents a developing country's socio-cultural adaptability to a developed country (Hamutoglu et al., 2020). Even higher education institutions are well established in the UK. The emergency implementation of online education will open a new window of practice, a developing country such as Pakistan. Higher education policymakers can adapt the best practices to recover the losses due to this global pandemic. 


\section{Sampling and data collection}

A convenience sampling technique was adopted to recruit participants for this study. Email communication has been sent out to conveniently available those ten students from the UK and ten from Pakistan who were enrolled in public and private universities in the master programs. However, collectively ten students approved an online interview (details are given in Table 1). Approachable students were information-rich and knowledgeable about the student experience phenomenon, considered primary criteria for this study's participants (Patton, 2002; Cresswell and Clark, 2011). The interview method was employed considering the new higher education student experience during this global pandemic. Social and physical distancing supported the online nature of interviews. Emergency management theory helped to craft an interview protocol.

Upon student confirmation about the day and time, virtual meeting applications (ZOOM and Hangouts) were used to conduct semi-structured interviews. The interview had two stages; the first stage covered demographic attributes such as gender, age, country, and discipline. In the second stage, participants were asked a series of questions probing wherever research felt appropriate; how did your university plan to respond in this emergency? What are the facilities provided by your university in this emergency? What kind of teacher-student relationship did you experience during online classes? How would your expectations vary between physical and digital interaction during classes? What kind of change e-learning brought into your learning processes? What are your suggestions for your university to be proactive for such emergencies? On average, every interview lasts for 20-25 minutes. Table 1 shows the sample profile of both study contexts (Study 1 for the Pakistani context and Study 2 for the UK context), gender (two females and eight males), age ranged between 20 and 40, and disciplines including management sciences and ad science and technology.

Table 1. Sample profile

\begin{tabular}{lllll}
\hline Participant No. & Context & Gender & Age & Discipline \\
\hline PK case 1 & Study 1 & Male & 20 & Management Sciences \\
PK case 2 & Study 1 & Female & 23 & Management Sciences \\
PK case 3 & Study 1 & Male & 23 & Management Sciences
\end{tabular}




$\begin{array}{lllll}\text { PK case } 4 & \text { Study } 1 & \text { Male } & 25 & \text { Management Sciences } \\ \text { PK case } 5 & \text { Study } 1 & \text { Female } & 22 & \text { Management Sciences } \\ \text { UK case } 1 & \text { Study } 2 & \text { Male } & 23 & \text { Management Sciences } \\ \text { UK case } 2 & \text { Study } 2 & \text { Male } & 21 & \text { Management Sciences } \\ \text { UK case } 3 & \text { Study } 2 & \text { Male } & 26 & \text { Science and Technology } \\ \text { UK case } 4 & \text { Study } 2 & \text { Male } & 40 & \text { Social Sciences } \\ \text { UK case } 5 & \text { Study } 2 & \text { Male } & 28 & \text { Management Sciences }\end{array}$

Note: Study 1= Pakistan, Study 2 = United Kingdom

\section{Data analysis}

After verbatim transcription, the data were analyzed using an inductive thematic analysis approach. Codes and themes were developed from the contents of the data semantically. The six phases (familiarization with the data, coding, generating initial themes, reviewing themes, defining and naming themes, and writing up) of the thematic analysis were adopted following a recursive approach. The graphical presentation is done to make the results more transparent and comparable. To report the challenges and solutions, data is presented in tabular form.

\section{Findings}

\section{Preparedness}

Appropriate steps taken before establishing a crisis to enhance its response and operability are known as preparedness in EMT (Wang et al., 2005). It includes pre-crisis training, resource management plans, public information in an emergency, etc. Emergency preparedness is essential to minimize the losses during an emergency. A research question was designed to examine the students' perceptions regarding emergency preparedness by higher education institutions (HEIs). The students believe that there was no preparation from the Pakistani context, not infrastructure, training or mental preparedness.

For example, one student mentioned that: 
"No, they were not prepared; we were just told that we will take classes online from now onwards. However, they did not train us (PK case 1, 20, male, management sciences (translated)).

Similarly, another student mentioned:

"No, there was no preparation for any emergency not in terms of training nor infrastructure" (PK case 2, 23, female, management sciences (translated)).

All the interviewees agreed on one point in terms of preparedness; one of them tried to highlight the reason as under:

"I do not think that they were prepared. I mean only those universities who are doing online education already like VU in Pakistan. Probably they had the system but not the other universities" (PK case 4, 25, male, management sciences).

The participant indicated that only one university (virtual university (VU)) is prepared for infrastructure and training, which is meant for online educational purposes. However, the other universities were not prepared. Therefore, due to unawareness of the e-learning process and technology use, students were initially reluctant to join online classes. The researcher also observed that students showed their concerns on the Facebook pages of the Higher Education Commission and the concerned university officials.

"In the beginning, we opposed this system as we had no expertise in the respective field. The session continued continuously, but it is disturbed and weird, and the university has not planned for this continuous session (PK case 5, 22, female, management sciences).

The students adopted this mode of learning forcefully. First, they felt that it was difficult, but now in terms of using e-tools, they feel that they are self-sufficient.

"We were confused at the time when we were told about online classes. Therefore, we did not agree; however, after using this medium, I found no issue" (PK case 2, 23, female, management sciences (translated)). 
Another insight was that the students who were already familiar with the technology found it easy to adopt online classes:

"Since we are familiar with the technology, and have learned many related skills during our 1st semester, it is not a big deal for us to adopt e-learning. Still we are not happy with this mode" (PK case 3, 23, male, management sciences (translated)).

"If I talk about myself, I am very much familiar with the software. I have been practising a lot on them. So it is easy for me. Well, I am not very sure that everyone is familiar with the use of this software. Because everyone is not an expert, for those who belong to rural areas, I would say it is difficult for them to cooperate" (PK case 4, 25, male, management sciences).

The United Kingdom has a diversified student body; especially, the current study focuses on international students. Highlights from the student's interviews are as under:

"I appreciate my university that they responded in a very professional way. They give us an option to sit at home and join lectures through online media" (UK case 5, 28, management sciences).

"University provided access to online classes through Microsoft teams application and reading material through Moodle (website)" (UK case 4, 40, male, social sciences).

However, two of the participants showed reservations:

"My University responded very late to this emergency, and my classes shifted online from $23^{\text {rd }}$ March 2020 before we received only emails from University about the regular situation which we are already aware of"' (UK case 1, 23, male, management sciences).

"We do not have any plan; we did not know what is going to happen? We have been informed that you need to stay home and we are online conducting classes. That is what going on; the situation is not in control, though" (UK case 3, 26, male, management sciences). 


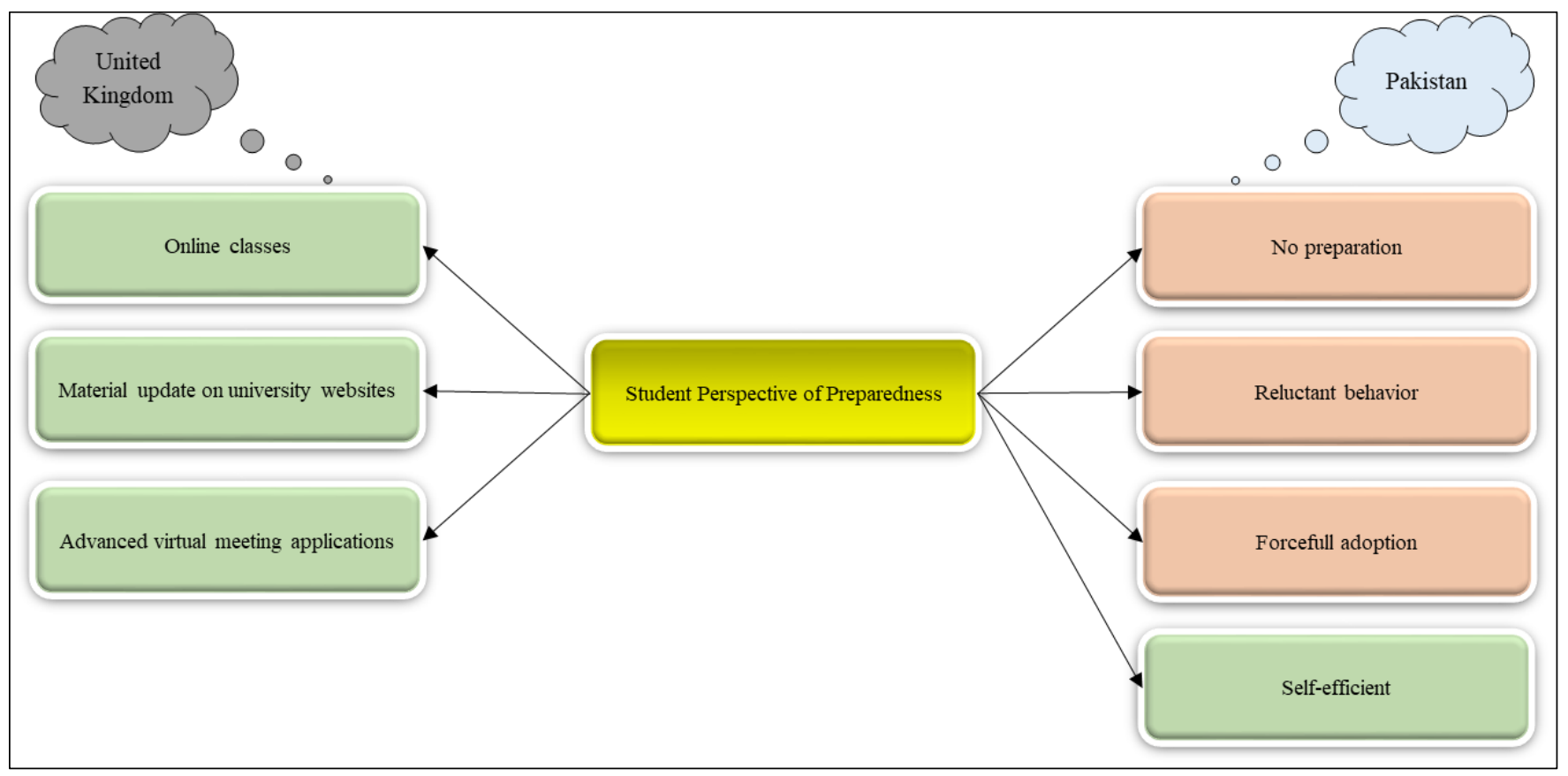

Figure 2. Student perspective regarding emergency preparedness

\section{Response}

In a crisis, appropriate steps taken to save people and avoid property damage and casualties are called "responses", according to EMT (Wang et al., 2005). The response is the management of available resources. In this case, universities and higher educational institutions (HEIs) are supposed to place all efforts and resources on implementing online classes, having technical support, etc. Therefore, it was inquired from students how HEIs responded to the global pandemic. The interview data analysis shows that Pakistani students were satisfied with the short-term response from HEIs. For example:

"I think they are very active, and they realize how important the time is for students" (Pkcase 4, 25, male, management sciences).

"We are informed of online classes that immediately after lockdown (within one week), and we were provided with LMS accounts on which the classes started" (Pk case 5, 22, female, management sciences). 
"As soon as the Government announced lockdown, with the gap of one week our classes were started" (Pk case 2, 23, female, management sciences (translated))

However, they showed concerns regarding providing any infrastructure (hardware, internet devices) and low data packages from the Higher Education Commission.

"The university did not offer us any infrastructure or training" (Pk case 1, 20, male, management sciences (translated)).

"The university offered no training or infrastructure; we were just told about online classes through social media accounts" (Pk case 3, 23, male, management sciences (translated)).

"As far as the equipment were concerned, I do not think that the university had enough time to even think about that because it all happened so quickly. The students have to manage all this equipment like laptops, internet connections, and many other factors to keep things going. It is totally up to the students they are doing all by themselves" (Pk case 4, 25, male, management sciences).

The respondents were further asked to suggest a long-term policy to meet any potential emergency. The students suggested that there must be a few mandatory online classes to have a blended experience during academic sessions. The data themes exposed that students understand that it is a new experience for their teachers, so strategic actions must make the virtual interaction effective. Although they believe that they can use e-tools, they still think e-learning is a different education model, requiring specialized training.

Here are a few verbatim examples:

"Universities should train students and should come up with a system that is user friendly" (Pk case 3, 23, male, management sciences (translated)).

"Specialized support should be planned for the students from rural areas, and the libraries should be prepared for this kind of emergencies integrating their services with university portals" (Pk case 2, 23, female, management sciences (translated)). 
"It is about making things easier for scholars also. Now we must ensure that the faculty members have the good skills on this software in delivering their lectures online" (Pk case 4, 25, male, management sciences).

On the other hand, the UK student believed that 'delayed response' (short term) and 'improved quality of interaction' (long term) are key challenges faced by the students.

One of the students mentioned the response:

"My University responded very late to this emergency, and my classes shifted online" (UK case 1, male, management sciences).

Moreover, prospectively, international students in the UK perceive positively the short-term actions taken by their universities, including; 'social distancing through online classes', and 'systematic response (awareness, shut down, social distancing)'. However, universities must put extra weight on 'implementing a robust training system' and 'strategies to implement' (frequent breaks, during classes, printed material, and fee discounts).

"University announced that your students would stay at home and you will receive updates regarding your lectures, your assignments and the academic work." (UK case 4, male, social sciences).

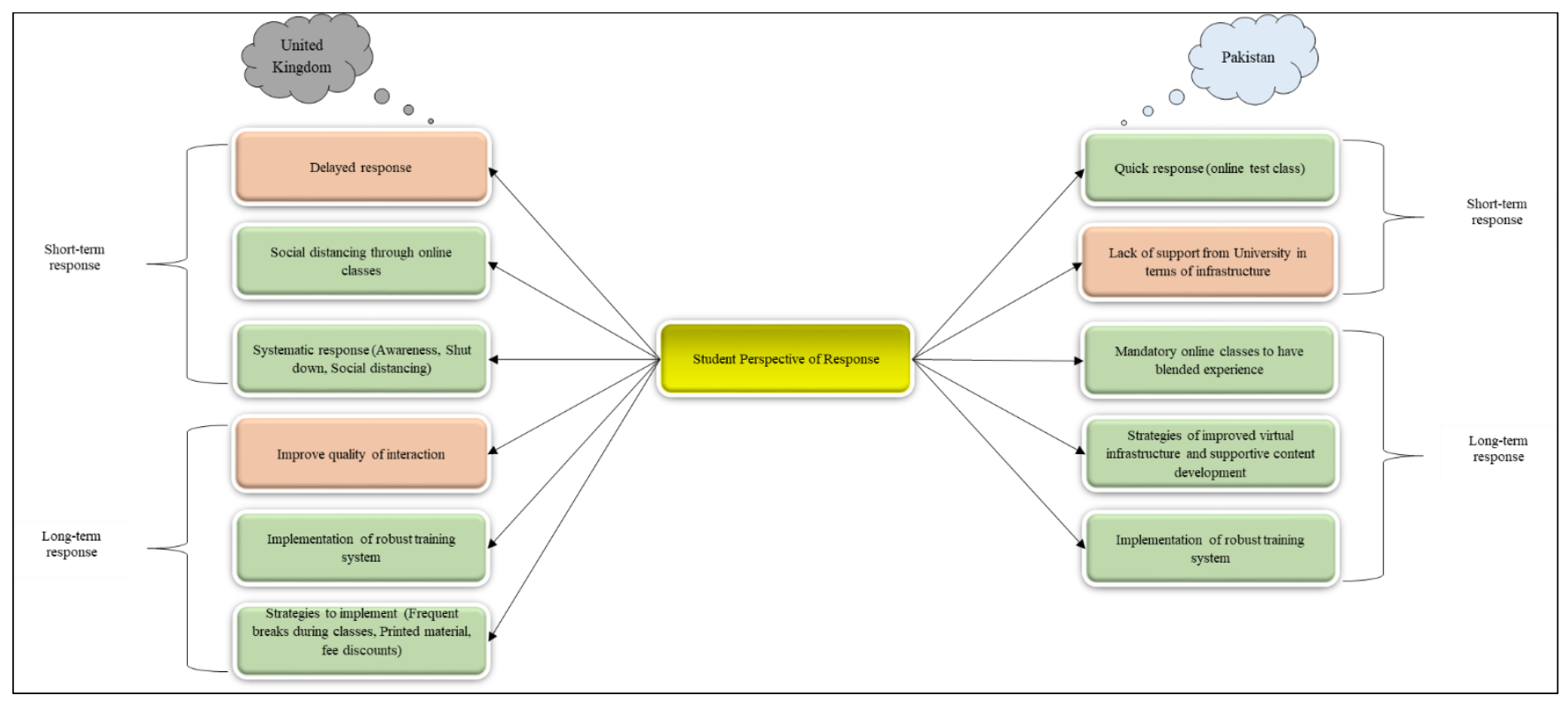

Figure 3. Student perspective regarding emergency response 


\section{Mitigation}

Adequate actions are taken to reduce the severity of the crisis, minimize its effects, and predict other future crises are known as mitigation (Wang et al., 2005). In the COVID pandemic, school closure was critically important. Modelling studies suggest that school closure has its greatest benefits in reducing transmission when schools are closed early in an outbreak (WHO). Strategies to address personal safety and well-being are also important. However, to minimize the educational loss, HEIs have taken certain actions. In response to our questions related to mitigation efforts carried out by HEIs, the research participants from Pakistan mentioned that they are receiving live lectures followed by discussion sessions, lecture recordings, and contents shared with the students. They can ask any question through the hand raise option in Zoom or through the chat option. Teachers ask personalized questions, take attendance, and assign graded activities to ensure all students' participation.

The student-teacher relationship depends on the internet connection; we use the chat option for discussion as if everyone switches on the mike, there is much noise. (PK case 3, 23, female, management sciences (translated))

Data were collected from three different universities, and all students mentioned that the students from remote areas could not join online classes.

I live in an area where I have to get good signals and connectivity (PK case 3, 23, female, management sciences (translated)).

"As everyone is not, I would say it is difficult for those who belong to rural areas to cooperate” (Pk case 4, 25, male, management sciences).

Students were not receiving any services from the library remotely (all cases agreed); they also mentioned that all students have different intellectual levels; a few students learn during group activities which are impossible nowadays. In addition, all of the students reported non-satisfactory student-teacher interaction as compared to the physical environment.

We try to take notes and ask questions, but the lecture goes on, whereas, in the physical environment, we can stop our teacher to clarify the concepts (PK case 3, 23, female, management sciences (translated)). 
"I think communication is the main hurdle during this e-learning" (PK case 5, 22, female, management sciences).

International students at UK universities expressed more concern in terms of mitigation activities initiated by universities. Notably, 'limited time for student-teacher consultancy' is shredding the student-teacher relationship. Furthermore, 'lack of interaction', 'lack of motivation', 'lack of class/group activities, and socialization touch towards learning is missing out here.

"Teacher and student relationship are very important. However, it is disturbed because of social distancing" (UK case 5, male, management sciences).

Alternatively, a few positive affirmations came out during the interview, including 'time and cost saver' as students can be available through a distance (no travelling cost, no formal dress). Specifically, one student expressed that 'teacher empathetic behaviour' is creating a positive space in the following words:

"That is a virtual relationship, though; in the virtual type of education, I do not think so that relationship can be built like this as the relationship we have now in the epidemic. However, I mean, my supervisor, she is more sympathetic now, more kind and careful" (UK case 4, male, social sciences). 


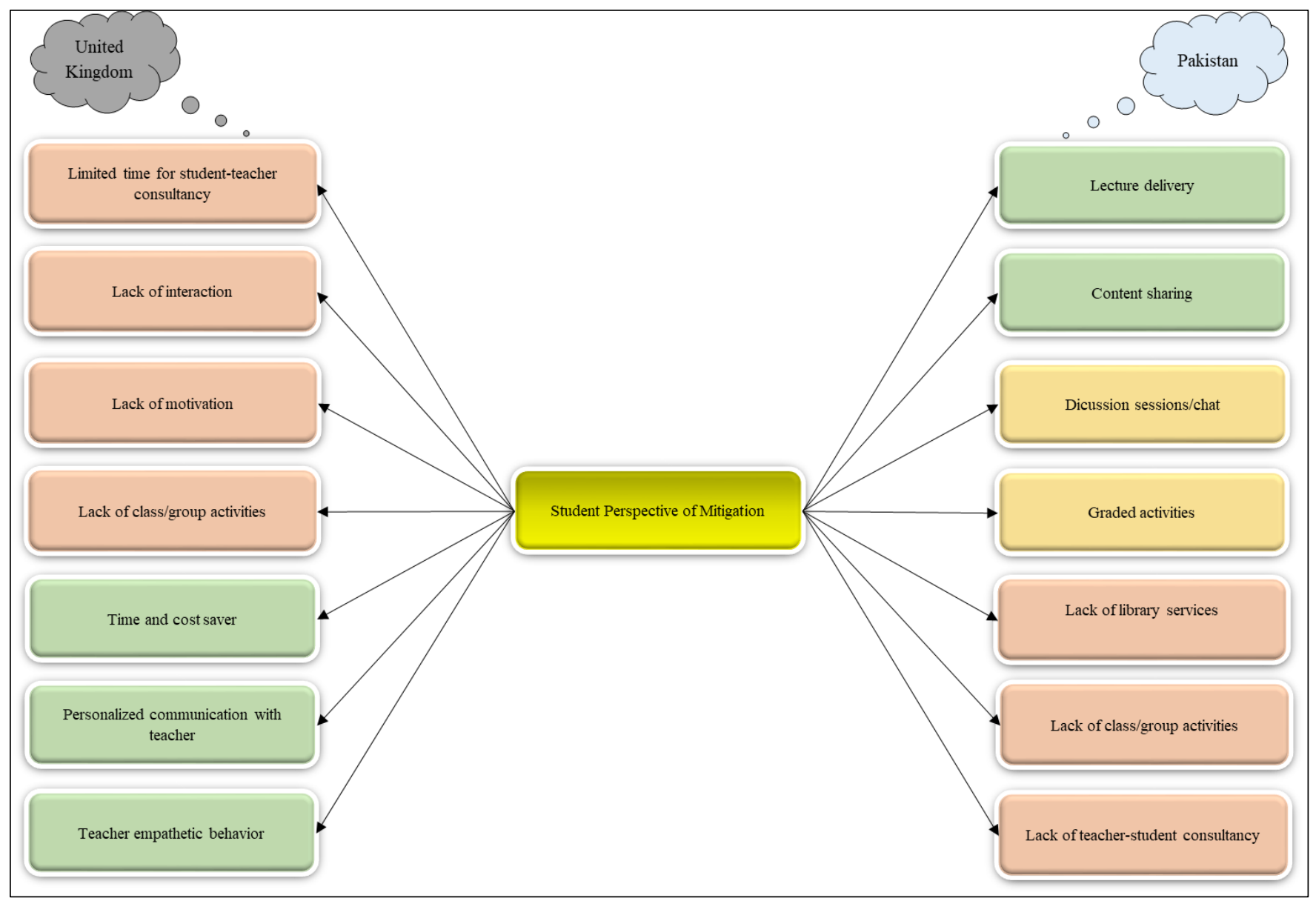

Figure 4. Student perspective regarding emergency mitigation

\section{Recovery}

Recovery is the action or process of regaining possession or control of something stolen or lost. Recovery relates to building capacity and stabilizing efforts. It is equally important to investigate how a response to the emergency mitigates recovery. Being optimistic, the students were also taking the current option (online classes) as an opportunity and mentioned that they would learn the technology's optimal use; they were feeling more responsible. Furthermore, they are not wasting their time, and their semesters are going on, which keeps them busy in the current panic situation.

"That is a great initiative to ensure that students are making their time productive at home; we are eventually saving much time" (PK case 4, 25, male, management sciences). 
Students reported that due to the students' problems from the remote areas, low-quality interaction with the teachers, poor internet connections, insufficient skills in using technological e-learning tools, affordability concerns, and lack of concentration (due to home environment) are big challenges the students. The students further noted that e-learning efforts could not be the same for all kinds of subjects.

"I enjoyed the e-Learning education experience and the relaxing situation, but after it grew very hectic, nothing sits around and feels that online classes break down mental health, but we do not have an option. I learned how to explore lectures on different platforms (google, different websites). I learned how to read before the particular topic; usually, before, I only depend on the class lecture and notes provided to us by the lecturer, but now due to the communication gap, I had to take the responsibility on my own.” (PK case 5, 22, female, management sciences).

International students at UK universities are curious about market exposure. Here, market exposure is the understanding of the open market. Due to lockdown, social distancing and elearning got dominance, and this situation has made the students are afraid to miss the opportunities to interact with people in the open market. However, the current situation of global pandemic is limiting the scope of 'market exposure'. The expectations of international students at UK universities were up; however, they face downtime in terms of 'learning opportunities', and a 'pressurized learning environment' where creativity is getting challenged. One of the participants mentioned about limitations of online classes:

"Online delivery of classes is getting more hike now, and the difference is that we are suffering somehow" (UK case 2, male, science, and technology)

"I am an international student, I came here for exposure. I am here for face to face meet up, events and other things. In my opinion, e-learning is not for me" (UK case 1, male, management sciences). 
In contrast, few students see positive prospects of this time, 'opportunity to adopt new learning strategies and 'virtual education - a big push to be responsible'. This can be comprehended through the following quote:

"So virtual education through virtual links makes us more responsible and more active. That is the change I am feeling" (UK case 4, male, social sciences).

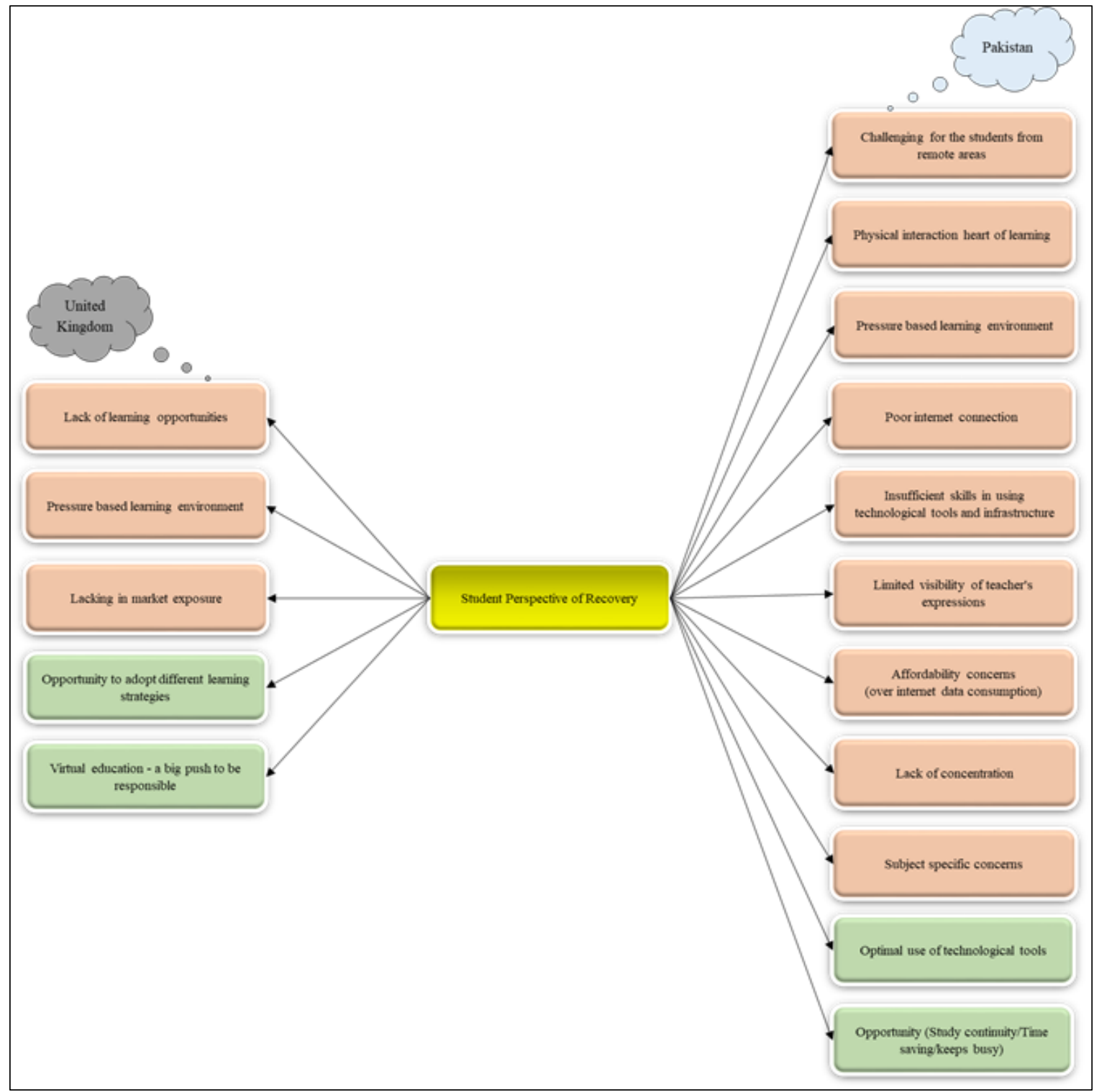

Figure 5. Student perspective regarding emergency recovery

\section{Discussion and conclusions}

The research findings revealed the challenges and prospects of e-education during the current pandemic, comparing two different contexts. Significant differences were noted in terms of the e- 
education approach between a developed and a developing country. Pakistani students are struggling with the online learning environment more than UK students. Contrary to the UK, Pakistan has no university web portals available to the students for online content and other relevant information. The students believe that the quality of education is questionable due to the reduced online teaching experience and limited infrastructure progress. However, the students believe that the instructors try to apply control strategies through discussions, personalized questions, and planning graded activities, i.e. assignments, term papers, and presentations, to bring students' attention to studies. Students learn from one another, which is why group activities are promoted through the higher education system. However, classroom group activities are missing in the online educational environment. Although group activities can be planned in a virtual environment, it seems missing as indicated by the responding students. Earlier studies confirmed differences and limitations in student-teacher relationships and feeling connected in the online educational environment compared to the traditional environment (Jensen et al., 2019).

Perhaps, Pakistan being a developing country, the students were not prepared to respond to alternative educational methods that require effective use of information technology and educational software, which are essential requirements for e-learning. However, it also seems that there was no emergency preparedness by HEIs. Still, there was no preparedness. The students were not trained to adopt e-learning. Students feel both cognitive and financial pressures to adopt this online system.

The digital divide in a developing country is a barrier to the recovery process (Shraim and Khalif, 2010; Simpson, 2018). Although Boateng et al., 2016, considered the developing country perspective suitable for e-learning adoption, however, Muries and Masele (2017) suggested that there is a need to explore the factors of embracing e-learning in developing countries, which include reasonable price, reliable access to the internet, and stable electricity connection as essential requirements for e-learning. A gap of technological know-how between a developed and developing country context is also required to be removed for e-learning adoption (Dasuki et al., 2015). As the HEIs were not prepared for e-education similarly, academic libraries (a by-product of HEIs) do not offer on-demand library services.

In Pakistan, teachers should be available for a considerable time to guide the students and learn how students are feeling. However, students feel a lack of connectivity and guidance in the current environment and are feeling overburdened. Bond et al., 2018 reported that the transformation of 
higher education through online education develops a sense of responsibility. Inversely, UK students shared that they are more connected with the instructors comparatively, and the teachers show empathetic behaviour. This difference of opinion may be the result of two different educational contexts. It is encouraging that students from both contexts feel that it is a good time to learn and use technology effectively, and it is a time-saving activity. Since digital technologies have become the norm in higher education (Helsper and Eynon, 2010; Lantz-Andersson et al., 2013), increasing the optimal use of technology is warranted. However, the UK respondents included international students, so they have serious concerns that they paid a handsome amount for foreign market exposure, which is missing these days. They reported that e-learning is not a choice but a forceful adoption, and they are studying under pressure.

The current research has applied the emergency management theory to develop a viable framework for enhancing a recovery process in the academic environment. Good literature has been produced during the last two decades regarding e-learning challenges. However, those studies addressed the phenomena in normal situations. The emergency is a different situation where only a few options are available to institutions, to the faculty and the students. In such an emergency (global pandemic), the current study is carried out under the lens of emergency management theory, and in the light of the research findings and the conclusions, viable solutions are proposed.

The study provided insights from two different contexts. First, the results and proposals may provide a clear guideline for the developing countries to develop a viable public policy in the education sector. In the context of Pakistan, there were numerous challenges in terms of Emergency management theory stages of preparedness (no preparation, reluctant behaviour, forceful adoption), response (lack of support from University in terms of infrastructure), mitigation (lack of library services), and recovery (the students from remote areas, physical interaction heart of learning, poor internet connection, insufficient skills in using technological tools and infrastructure, limited visibility of teacher's expressions, affordability concerns, lack of concentration, subject-specific concerns).

Students from Pakistan have given a few solutions in any future global pandemic. For example, a few mandatory online classes were suggested to conduct during each semester to have a blended experience during academic sessions. They further suggested that using e-tools is not the only requirement, but e-learning requires specialized training. Based on their insights, the researchers can safely suggest that a clear, step-by-step uniformed guideline by HEIs about evaluation 
strategies, content coverage, and practical subjects may reduce students' anxiety. Once the emergency gets over, based on the practical experience and the best practices, a proper emergency management plan should be developed by the education department generally and higher education departments specifically. An online survey should be conducted at the mass level to understand and sort out the students' issues, and recovery steps should be taken accordingly. Since the students were not receiving any library services, it can be suggested that personalized remote library services should be started immediately. Since the digital divide is a big challenge for the students, Pakistan's government should take serious steps to help the non-affording students. It is a worldwide phenomenon (Shraim and Khalif, 2010), and its affordability is a big challenge in adopting e-learning.

On the other side, students at higher education institutions in the UK perceive the following challenges at every stage of emergency management theory; response (delayed response, improve quality of interaction), mitigation (lack of interaction, lack of motivation) and recovery (lack of learning opportunities, lacking in market exposure). Students in the Pakistani and British higher education institutions face common challenges at the mitigation stage (lack of teacher-student consultancy, lack of class/group activities) and recovery stage (pressure-based learning environment). However, there could be the following solutions to similar future emergencies; a strategic plan by HEIs for designing online content can improve online classes' quality. Counselling sessions should be conducted to educate the students that online education systems have certain limitations and cannot be compared with the physical environment. Compensation strategies (fee reduction, special classes) should be devised and conveyed to them, particularly for international students. Comparatively, the students were not mentally prepared; there is a feeling of uncertainty and anxiety among them. A strong counselling campaign should be driven by the HEIs, ensuring they compensate them as the situation gets better.

Given the comparative context among developing and developed higher education institutions, students from both countries, Pakistan and the UK, have different perceptions and experiences during the global pandemic emergency regarding getting ready, identifying the alternative methods of teaching, upcoming challenges, and their potential solutions. Even though the UK has a developed higher education context, students indicated numerous concerns, especially comparing the high cost of education and online classes. Students are looking for facilitation in cost reduction of the tuition fee. Alternatively, students in the Pakistani higher education context were more 
concerned about online classes' infrastructure and demanding behavioural change in the higher education institutions. The current study results guide policymakers to develop contingency planning to address students' key challenges. For example, students from the UK are not experiencing a serious challenge of infrastructure. However, the lack of student-instructor interaction becomes an appealing challenge. Hence, policymakers from both countries need to understand the contextual challenges vigilantly and implement proposed solutions such as emergency management plans for higher education students and the regular hybrid (online and offline) classes.

\section{References}

Adnan, M., and Anwar, K. (2020), “Online Learning amid the COVID-19 Pandemic: Students' Perspectives", Journal of Pedagogical Sociology and Psychology, Vol. 2 No.1, pp. 45-51.

Al-Samarraie, H., Teng, B. K., Alzahrani, A. I., and Alalwan, N. (2018), "E-learning continuance satisfaction in higher education: a unified perspective from instructors and students", Studies in Higher Education, Vol. 43 No.11, pp. 2003-2019

Asghar, M. Z., Barberà, E., and Younas, I. (2021), "Mobile learning technology readiness and acceptance among pre-service teachers in Pakistan during the COVID-19 pandemic", Knowledge Management and E-Learning: An International Journal, Vol. 13 No. 1, pp. 83101.

Affouneh, S., Salha, S., N., and Khlaif, Z. (2020), "Designing quality e-learning environments for emergency remote teaching in coronavirus crisis: Interdisciplinary Journal of Virtual Learning in Medical Sciences, Vol. 11 No.2, pp.1-3.

Bao, W. (2020), "COVID-19 and online teaching in higher education: A case study of Peking University", Human Behavior and Emerging Technologies, Vol. 2 No. 2, pp. 113-115.

Bacow, L., Meng, X. L., and Vittert, L. (2020). A Conversation with Larry Bacow on the Impact of COVID-19. Special Issue 1-COVID-19.

Basilaia, G., Dgebuadze, M., Kantaria, M., and Chokhonelidze, G. (2020), "Replacing the classic learning form at universities as an immediate response to the COVID-19 virus infection in Georgia", International Journal for Research in Applied Science and Engineering Technology, Vol. 8 No.3, pp. 101-8. 
Boateng, R., Mbrokoh, A. S., Boateng, L., Senyo, P. K., and Ansong, E. (2016), “Determinants of e-learning adoption among students of developing countries", The International Journal of Information and Learning Technology. Vol. 33 No. 4, pp. 248-262

Bond, M., Marín, V. I., Dolch, C., Bedenlier, S., and Zawacki-Richter, O. (2018), "Digital transformation in German higher education: student and teacher perceptions and usage of digital media", International Journal of Educational Technology in Higher Education, Vol.15 No.1, pp. 48.

Cresswell, J. W., and Poth, C. N. (2007), "Qualitative inquiry and research method: Choosing among five approaches", Thousand Oaks, CA: Sage.

Cresswell, J. W., and Clark, V. L. P. (2011), “Designing and conducting mixed methods research”, Sage publications.

Dasuki, S. I., and Abbott, P. (2015), “A socio-technical analysis of ICT investments in developing countries: A capability perspective", The Electronic Journal of Information Systems in Developing Countries, Vol. 67 No. 1, pp. 1-29.

Eltahir, M. E. (2019), "E-learning in developing countries: Is it a panacea? A case study of Sudan”, IEEE Access, Vol.7, pp. 97784-97792.

Fisher, M., and Coleman, B. (2001), “Collaborative online learning in virtual discussions", Journal of Educational Technology Systems, Vol. 30 No. 1, pp. 3-17.

Fuster Guillen, D. E. (2019), “Qualitative Research: Hermeneutical Phenomenological Method”, Journal of Educational Psychology-Propositos y Representaciones, Vol. 7 No. 1, pp. 217229.

Hamutoglu, N. B., Gemikonakli, O., De Raffaele, C., and Gezgin, D. M. (2020), "Comparative Cross-Cultural Study in Digital Literacy", Eurasian Journal of Educational Research, Vol. 88, pp. 121-147.

HEC (2021), "Recognized Universities", HEC Pakistan official website. Available at: https://www.hec.gov.pk/english/universities/pages/recognised.aspx (Accessed on 08th May, 2021).

Helsper, E. J., and Eynon, R. (2010), “Digital natives: where is the evidence?”, British Educational Research Journal, Vol. 36 No. 3, pp. 503-520. 
Henderson, M., Selwyn, N., and Aston, R. (2017), "What works and why? Student perceptions of 'useful digital technology in university teaching and learning", Studies in Higher Education, Vol. 42 No. 8, pp. 1567-1579.

Jensen, L., Price, L., and Roxå, T. (2019), "Seeing through the eyes of a teacher: differences in perceptions of HE teaching in face-to-face and digital contexts", Studies in Higher Education, Vol. 45 No. 6, pp.1149-1159.

Knox, C.C. and Haupt, B. (2015), "Incorporating cultural competency skills in emergency management education", Disaster Prevention and Management, Vol. 24 No. 5, pp. 619634.

Kreft, S., Eckstein, D., Junghans, L., Kerestan, C., and Hagen, U. (2013), “Global climate risk index 2014", Who Suffers Most from Extreme Weather Events, 1.

Lantz-Andersson, A., Vigmo, S., and Bowen, R. (2013), "Crossing boundaries in Facebook: Students' framing of language learning activities as extended spaces", International Journal of Computer-Supported Collaborative Learning, Vol. 8 No. 3, pp. 293-312.

Liguori, E. W., and Winkler, C. (2020), "From offline to online: Challenges and opportunities for entrepreneurship education following the COVID-19 pandemic", Entrepreneurship Education and Pedagogy, Vol. 3 No 4, pp. 346-351.

Murphy, M.P. (2020), “COVID-19 and emergency eLearning: consequences of the securitization of higher education for post-pandemic pedagogy", Contemporary Security Policy, Vol. 14 No. 3, pp. 492-505.

Mayhew, M. J. (2004), "Exploring the essence of spirituality: A phenomenological study of eight students with eight different worldviews", NASPA Journal, Vol. 41 No.4, pp. 647-674.

Muries, B., and Masele, J. (2017), “Explaining electronic learning management systems (ELMS) continued usage intentions among facilitators in Higher Education Institutions (HEIs) in Tanzania”, International Journal of Education and Development Using ICT, Vol. 13 No. 1, pp. 123-141.

Pimmer, C. (2016), "Mobile learning as boundary crossing: an alternative route to technologyenhanced learning?”, Interactive Learning Environments, Vol. 24 No. 5, pp. 979-990.

Prasolova-F, E., Molka-Danielsen, J., Fominykh, M., and Lamb, K. (2017), “Active learning modules for multi-professional emergency management training in virtual reality", IEEE 
6th International Conference on Teaching, Assessment, and Learning for Engineering (TALE) pp. 461-468.

Patton, M. Q. (2002), “Qualitative research and evaluation methods", $3 d$ ed. Thousand Oaks, CA: Sage.

Rehman, M. A., Woyo, E., Akahome, J. E., and Sohail, M. D. (2020). The influence of course experience, satisfaction, and loyalty on students' word-of-mouth and re-enrolment intentions. Journal of Marketing for Higher Education, pp. 1-19.

Renda dos Santos, L. M., and Okazaki, S. (2016), "Planned e-learning adoption and occupational socialization in Brazilian higher education", Studies in Higher Education, Vol. 41 No. 11, pp. 1974-1994.

Rieley, J. B. (2020), “Corona Virus and its impact on higher education”, Research Gate.

Ramaiah, C. K. (2014), "Emerging trends in electronic learning for library and information science professionals", Knowledge, Library and Information Networking, pp. 328-350.

Soroya, S. H., Rehman, M. A., Abbas, Z., Mirza, F., and Mahmood, K. (2020), "Emergency management in higher education during COVID-19 pandemic: A phenomenology inquiry comparing a developed and developing country", Library Philosophy and Practice.

Saavedra, J. (2020), "Educational challenges and opportunities of the Coronavirus (COVID-19) pandemic", World Bank Blogs. Available at: https://blogs.worldbank.org/education/educational-challenges-and-opportunities-covid19-pandemic (Accessed 29 November 2020)

Saeed, M. (2007), "Education System of Pakistan and the UK: Comparisons in Context to Interprovincial and Inter-countries Reflections", Bulletin of Education and Research, Vol. 29 No. 2, pp. 43-57.

Saleem, M., Kamarudin, S., Shoaib, H. M., and Nasar, A. (2021), "Influence of augmented reality app on intention towards e-learning amidst COVID-19 pandemic", Interactive Learning Environments, pp. 1-15.

Sharpe, R., and Benfield, G. (2005), "The student experience of e-learning in higher education", Brookes eJournal of Learning and Teaching, Vol. 1 No. 3, pp. 1-9.

Shehzadi, S., Nisar, Q.A., Hussain, M.S., Basheer, M.F., Hameed, W.U. and Chaudhry, N.I. (2020), "The role of digital learning toward students' satisfaction and university brand 
image at educational institutes of Pakistan: a post-effect of COVID-19”, Asian Education and Development Studies.

Shraim, K., and Khlaif. Z. (2010), “An e-learning approach to secondary education in Palestine: Opportunities and challenges", Information Technology for Development, Vol. 16 No. 3, pp. 159-173.

Singh, V., and Thurman, A. (2019), "How many ways can we define online learning? A systematic literature review of definitions of online learning", American Journal of Distance Education, Vol. 33 No. 4, pp. 289-306.

Siron, Y., Wibowo, A., and Narmaditya, B. S. (2020), "Factors affecting the adoption of e-learning in Indonesia: Lesson from Covid-19”, Journal of Technology and Science Education, 10(2), pp. 282-295.

Simpson, O. (2018), “Supporting students in online, open and distance learning”, Routledge. Sohrabi, C., Alsafi, Z., O’ Neill, N., Khan, M., Kerwan, A., Al Jabir, A., Iosifidis, C. and Agha, R. (2020), "World Health Organization declares global emergency: a review of the 2019 novel coronavirus (COVID19)”, International Journal of Surgery, Vol. 76 pp. 71-76.

STATISTA (2020), "Share of individuals using online learning materials and doing online courses in Great Britain in 2020, by age and gender". Available at: https://www.statista.com/statistics/882117/online-learning-in-the-uk-by-demographic/

(Accessed on 08th May, 2021).

Wang, F., Xu, Z., Pan, Y., and Guang-wang, S. E. Y. (2005), "Study on compiling technique for emergency rescue protocol of accident in enterprise", China Safety Science Journal, Vol. 15 No. 4, pp. 101-112.

Weeden, K. A., and Cornwell, B. (2020), "The small-world network of college classes: implications for epidemic spread on a university campus", Sociological Science, Vol. 7, pp. 222-241.

Wright, F., White, D., Hirst, T., and Cann, A. (2014), "Visitors and Residents: mapping student attitudes to academic use of social networks", Learning, Media and Technology, Vol. 39 No. 1, pp. 126-141.

Zhou, X., and Milecka-Forrest, M. (2021), “Two groups separated by a shared goal: how academic managers and lecturers have embraced the introduction of digital technologies in UK Higher Education”, Research in Learning Technology, Vol. 29, pp. 1-18. 